\title{
Modelização espacial, comunicação e memória cultural no bairro Lavapiés, em Madrid: a questão das corralas
}

\section{Spatial modeling, communication and cultural memory of Lavapiés neighborhood in Madrid: the question of corralas}

Regiane Miranda de Oliveira Nakagawa ${ }^{1}$

Resumo: Tendo por base o conceito de memória cultural não hereditária, proposto pelo semioticista da cultura Iuri Lotman, este artigo apresenta uma análise das corralas, um tipo de habitação popular presente no bairro Lavapiés, em Madrid, que será explorado como um texto cultural, e o modo pelo qual esse símbolo é traduzido no cartaz de divulgação das Fiestas Populares de Lavapiés de 2019. Com isso, objetiva-se pontuar a existência de um modelo subjacente a essas habitações, à qual se vincula um sentido de participação e coletividade, e como esses sentidos são ressignificados na peça gráfica. Por meio da memória, busca-se ainda explicitar de que maneira, de acordo com a perspectiva semiótica, os processos comunicacionais ocorrem na esfera da urbe.

Palavras-chave: memória cultural não hereditária; cidade; comunicação; coletividade.

Abstract: Based on the concept that cultural memory is not hereditary, as proposed by the culture semiotician Yuri Lotman, this article presents an analysis of the corralas, a type of popular housing found in the Lavapiés neighborhood in Madrid. This kind of housing will be explored as a cultural text, and the general manner in which this symbol is translated in the poster promoting the Fiestas Populares de Lavapiés de 2019. Therefore, the aim of this article is to punctuate

1 Universidade Federal do Recôncavo da Bahia (UFRB). Cruz das Almas, BA, Brasil.

https://orcid.org/0000-0002-2039-7610 E-mail: regianemo@uol.com.br 
the existence of a subjacent model to these housing dwells that is linked to a sense of participation and collectivity, and how these senses are re-signified in the printed poster. Through memory, we also seek to explain how, according to the semiotic perspective, communicational processes occur in the sphere of the city.

Keywords: non-hereditary cultural memory; city; communication; collectivity. 


\section{Introdução}

Situado na região central de Madrid, Lavapiés é, junto com El Rastro, popularmente conhecido como um dos "bairros baixos" da capital espanhola, designação essa decorrente, segundo Osorio (2017), de dois fatores. O primeiro deriva de uma causa geográfica, uma vez que ambos os bairros estão situados numa descida que termina no rio Manzanares, localizado numa região geograficamente baixa da cidade.

O segundo está ligado a fatores históricos, pois, a partir do século XVI, Lavapiés e El Rastro atraíram grande contingente de migrantes oriundos, sobretudo, de áreas agrárias da Espanha, primeiramente em virtude dos matadouros públicos que ali se instalaram e, posteriormente, por ter se transformado em zona industrial, o que tornou a região altamente populosa. Seus habitantes viviam em condições materiais extremamente precárias, reforçando, assim, a associação do bairro a algo "baixo".

Foi nesse contexto que, sobretudo no Século XIX, houve grande expansão das corralas², um tipo de habitação popular criado em consequência do déficit habitacional ocasionado pelo grande afluxo populacional presente na região. Trata-se das chamadas "casas de corredor”, construções com alguns andares, edificadas em torno de um pátio central que abrigavam habitações extremamente pequenas, as quais possuíam em torno de $20 \mathrm{~m}^{2}$, acessíveis por meio de corredores abertos, voltados ao pátio. Comumente, em cada andar, havia apenas um banheiro e uma cozinha, que eram compartilhados por aqueles que ali residiam. Como ressalta Osorio (2017), eram espaços com pouquíssima privacidade, utilizados quase que exclusivamente para dormir. O grande pátio situado no centro da edificação tornava a convivência com os vizinhos praticamente compulsória, pois parte do cotidiano e da vida daqueles que ali residiam se dava, de fato, na parte externa da habitação. Assim, as corralas constituíram-se à semelhança de pequenas comunidades.

Nas últimas décadas, as corralas passaram por um processo de revitalização financiado pelo poder público e tornaram-se moradias que,

2 A palavra corrala vem do latim carrus, carro (em espanhol), e designava um espaço comumente circular, rodeado por uma vala ou muro. 
mesmo pequenas, em sua maioria, possuem banheiro e cozinha próprios. Muitas delas ainda podem ser encontradas pelo bairro (figura 1) (figura 2), e uma das maiores é ocupada pelo Centro Cultural La Corrala. Museo de Artes y Tradiciones Populares, vinculado à Universidad Autónoma de Madrid (figura 3) (figura 4) (figura 5). Atualmente, Madrid é a cidade com a maior quantidade de "casas de corredor" no mundo (OSORIO, 2017).

Figura 1 - Pátio de corrala em Lavapiés

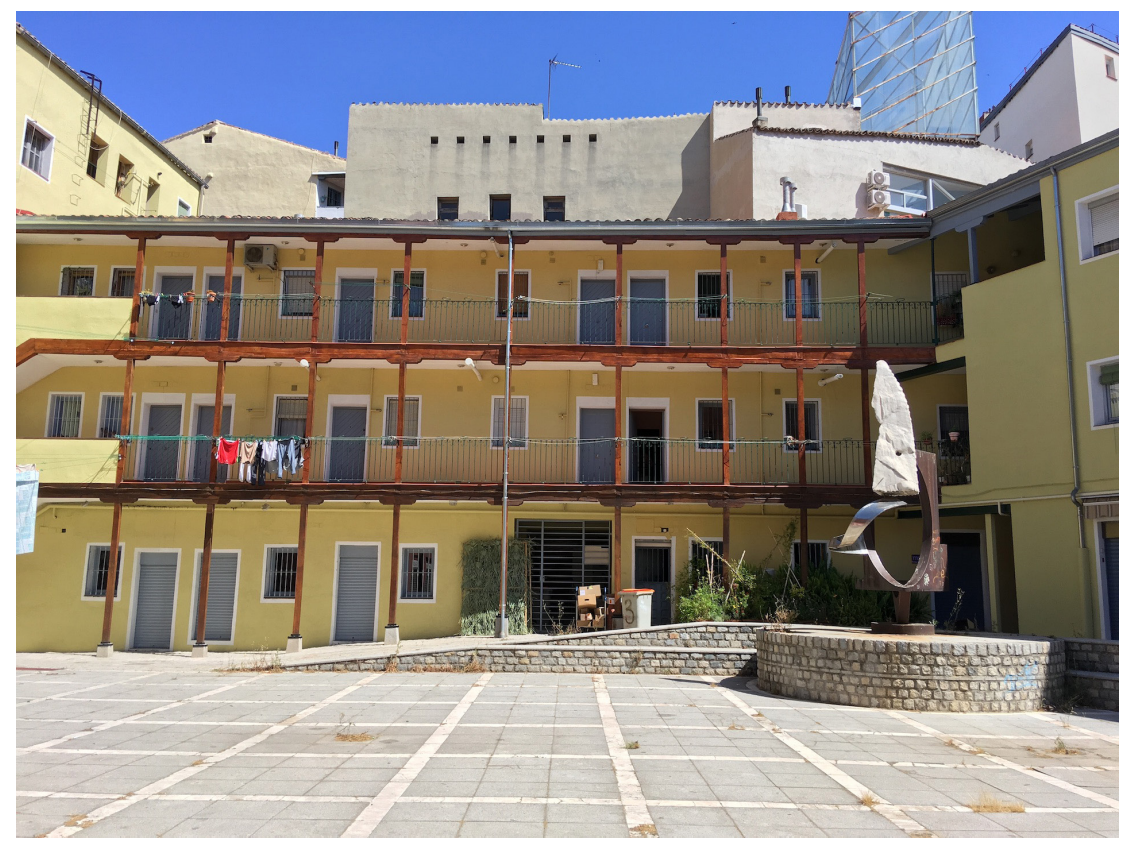

Fonte: Autora 
Figura 2 - Pátido de corrala em Lavapiés

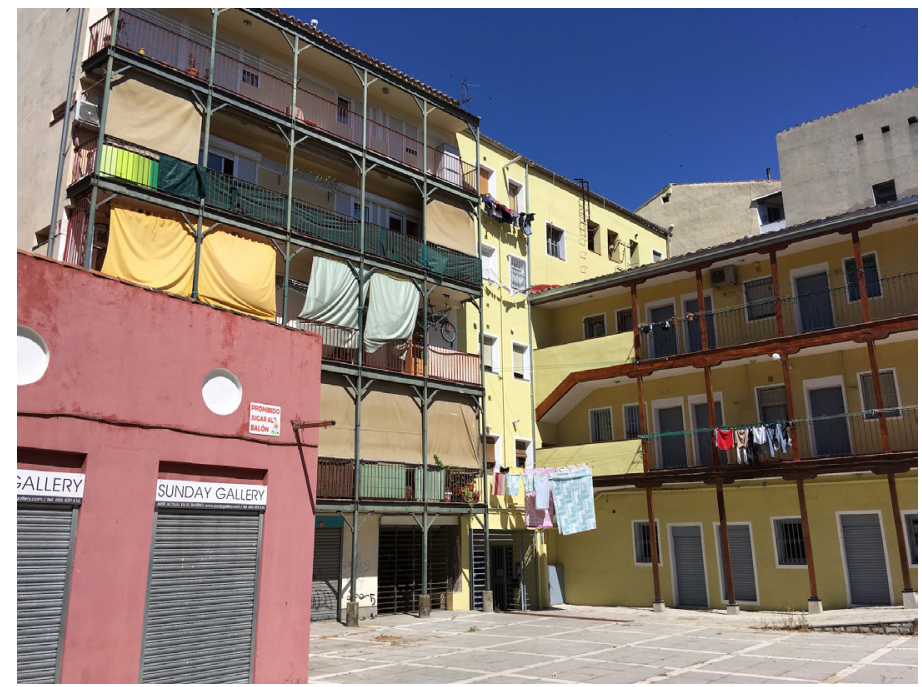

Fonte: Autora

Figura 3: Fachada do Museo de Artes y Tradiciones Populares em Lavapiés

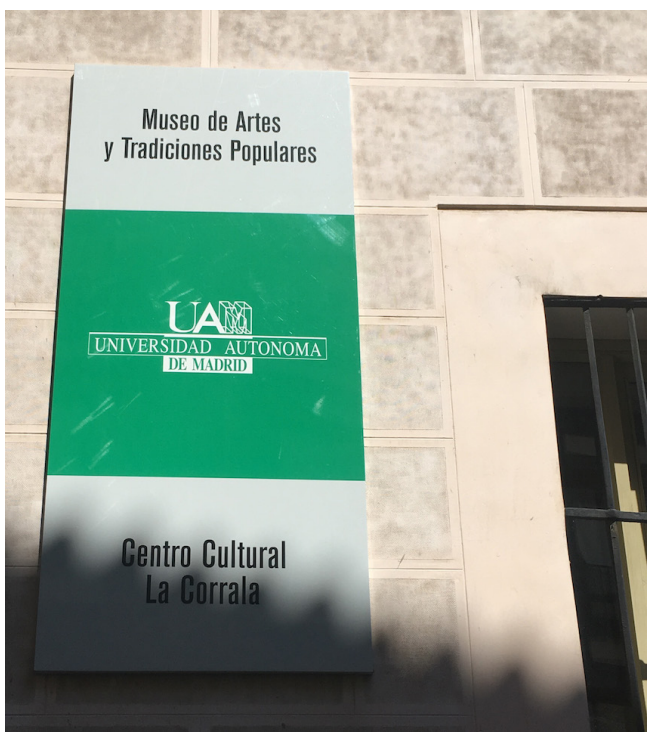

Fonte: Autora 
Figura 4: Pátio interno do Museo de Artes y Tradiciones Populares em Lavapiés

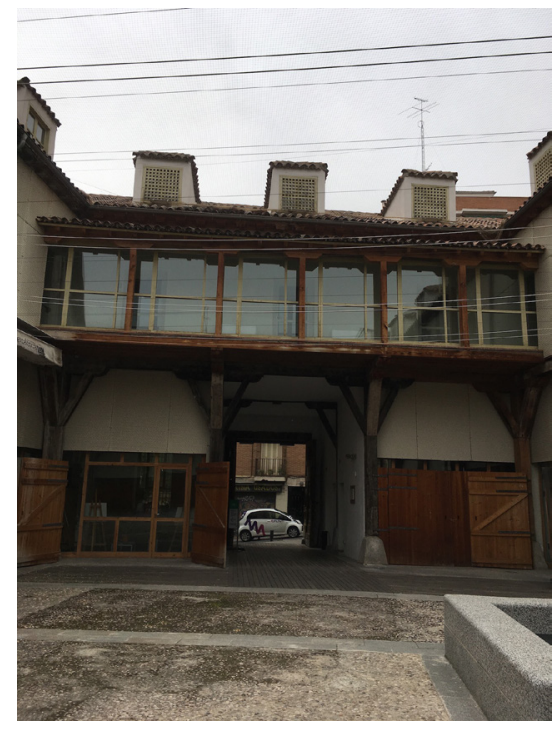

Fonte: Autora

Figura 5: Pátio interno do Museo de Artes y Tradiciones Populares em Lavapiés

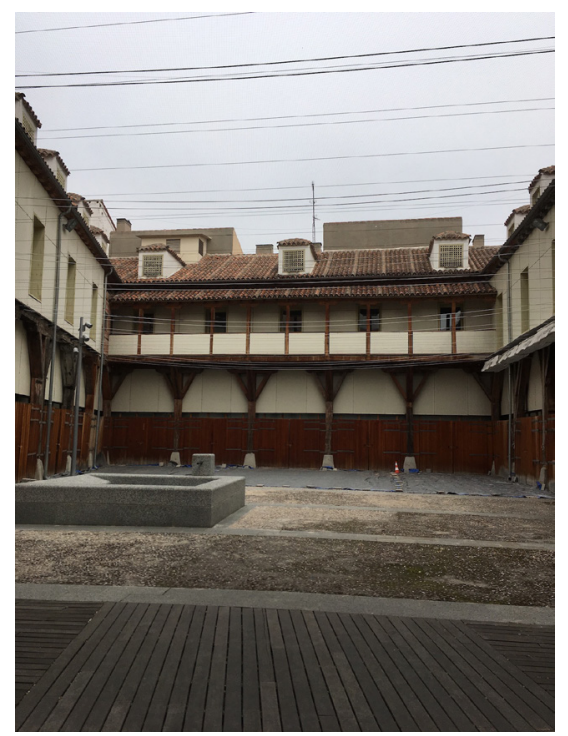

Fonte: Autora 
Ainda que breve, esse pequeno histórico oferece-nos uma ideia das razões pelas quais essas habitações vieram a ser um importante símbolo do bairro. Não é à toa que sua associação de vizinhos se chama $L a$ corrala (figura 6), da mesma forma que inúmeras são as alusões feitas às corralas nos materiais de divulgação dos eventos que ocorrem na região.

Figura 6: Fachada da Associação de vizinhos La corrala

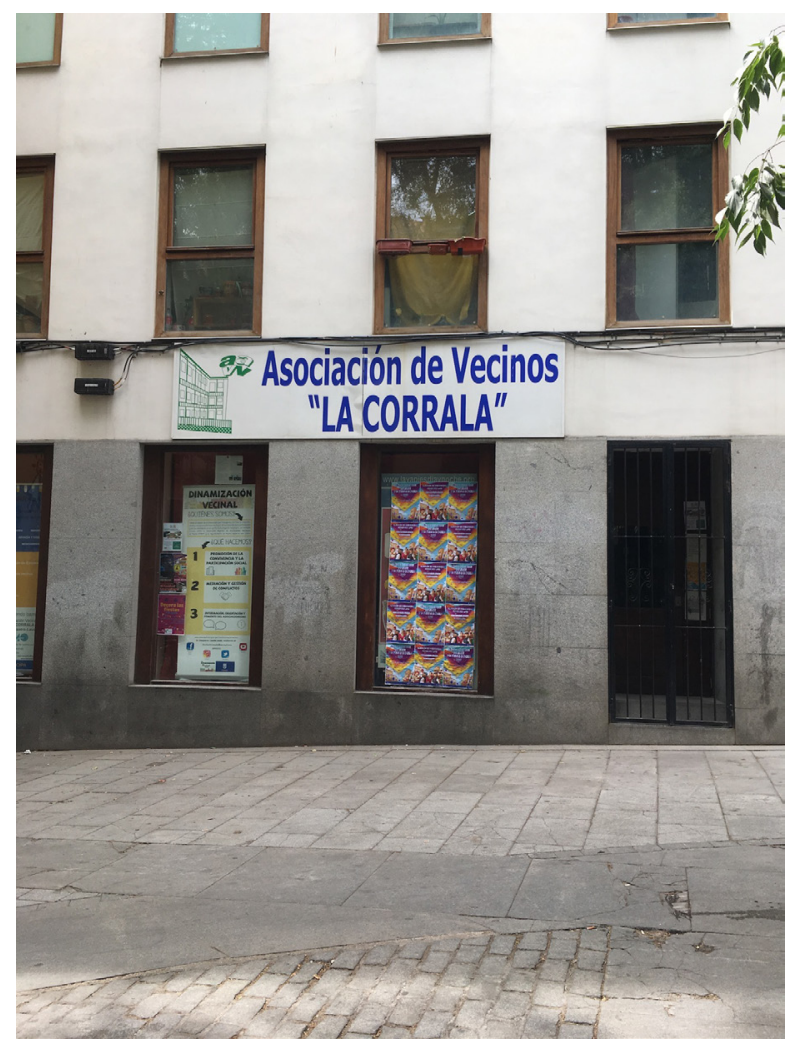

Fonte: Autora

Para além desses usos e sentidos manifestos, neste artigo, interessa-nos pontuar em que medida as corralas podem ser entendidas como espacialidades de memória no referido bairro, das quais decorre a construção de sentidos relacionados à ideia de coletividade e pertencimento 
comumente associados à região. Também buscaremos situar de que maneira tal signo mnemônico constrói uma reverberação própria na relação que estabelece com outras linguagens, de modo a amplificar e ressignificar os sentidos vinculados à vida comunal, tal como ocorre no cartaz de divulgação das Fiestas Populares de Lavapiés ${ }^{3}$ de 2019, que será analisado na última parte deste texto.

Cumpre destacar que a discussão aqui proposta faz parte de uma pesquisa mais ampla, realizada no bairro Lavapiés, voltada a apreender a constituição das suas diferentes espacialidades (FERRARA, 2002, 2008) e os sentidos que elas geram na cultura. Para tal, durante o período de 7 meses, de janeiro a julho de 2019, foram feitas inúmeras derivas (DEBORD, 2003) na região, além da realização de conversas informais com moradores e historiadores, entrevistas semiestruturadas, passeios guiados e pesquisa bibliográfica, os quais nos permitiram delinear a presença de diferentes dominantes (JAKOBSON, 1983) no bairro, tendo em vista o reconhecimento dos modos de funcionamento de suas distintas espacialidades e das funções por elas exercidas.

Como Kull aponta, “[...] estabelecer distinções é, de algum modo, também um método” (2007, p. 76). Em conformidade com tal linha de raciocínio, por meio da discriminação de diferenças e posições, tornou-se possível apreender como a memória se coloca como um traço marcante e dominante das corralas quando vistas no âmbito do espaço semiótico de relações que se constrói no bairro Lavapiés.

É importante ressaltar que nosso caminho investigativo toma por base o raciocínio inerente àquilo que Machado (2002) situa como "problema semiótico". De acordo com tal viés, o foco do processo investigativo passa a ser a explicitação da maneira pela qual, em semiose, as linguagens e os códigos culturais geram novas mensagens e/ou textos que, por sua vez, produzem novos sentidos ou ressignificam aqueles já existentes. Como a autora afirma, "o problema semiótico em vez de responder ao por que procura explicitar o 'como', sempre como um exercício

3 As Fiestas populares de Lavapiés são também conhecidas como trilogía verbena de agosto, formada pelas festas de San Cayetano, San Lorenzo e La Paloma. O cartaz foi idealizado por Marion Cassabalian, moradora do bairro. 
crítico" (MACHADO, 2002, p. 214). Assim, apreender por intermédio de qual mecanismo as corralas se articulam como espacialidades que se constroem como textos culturais mnemônicos relacionados à vida em coletividade, que, por sua vez, levam à formação de outros textos e à ressignificação do sentido de comunidade, tal como ocorre no referido cartaz, constitui o centro da nossa discussão.

Em correlação a Machado, tal abordagem também se ampara na perspectiva epistemológica de estudo da cultura vinculada à semiosfera, definida por Iuri Lotman (1996), um dos principais representantes da Escola de Tartu-Moscou (ETM), como o espaço semiótico de relações continuamente edificado e redefinido pelos intercâmbios e tensionamentos estabelecidos entre os mais distintos sistemas de linguagem presentes na cultura por meio da fronteira semiótica.

No âmbito da semiosfera, conforme será discutido, a memória constitui-se como um dispositivo que exerce uma dupla função, uma vez que ela tanto é responsável por assegurar a continuidade dos sistemas, quanto por incitar a criação de novos textos culturais. É igualmente por meio da memória que, por fim, buscaremos explicitar de que maneira, de acordo com a perspectiva semiótica, os processos comunicacionais ocorrem na esfera da urbe, pelos quais ela é continuamente redefinida. Aqui, é importante situar que, para os semioticistas da ETM, a comunicação é entendida, essencialmente, como “[...] um processo de complicação progressiva [...]”4 (LOTMAN, 1996, p. 67), fruto das relações continuamente redefinidas entre diferentes sistemas, pelas quais, inclusive, a memória não hereditária se faz atuante na cultura. Vejamos mais detalhadamente como esse processo pode ser entendido.

\section{Cidade e memória}

Ainda que poucas tenham sido as alusões feitas por Lotman à cidade ao longo dos seus estudos, o semioticista não desconsiderou a maneira pela qual ela pode ser compreendida por meio da correlação continuamente

4 Na tradução espanhola: “[...] un proceso de complicación progresiva [...]”. 
edificada e redefinida entre variadas formações sígnicas, bem como pelas diferentes temporalidades que as caracterizam. Segundo o autor:

Precisamente o poliglotismo semiótico de qualquer cidade a converte em campo de diferentes colisões semióticas, impossíveis em outras circunstâncias. Ao unir códigos e textos diferentes quanto ao estilo e significação nacional e social, a cidade realiza hibridações, recodificações e traduções semióticas que a transformam em um poderoso gerador de nova informação. Fonte de tais colisões semióticas não é apenas o encontro sincrônico de formações semióticas heterogêneas, mas também a diacronia: as construções arquitetônicas, os rituais e cerimônias urbanas, o próprio plano da cidade e milhares de outros restos de épocas passadas atuam como programas codificados que produzem de novo, permanentemente, os textos do passado histórico. A cidade é um mecanismo que recria seu passado e, assim, obtém a possibilidade de encontrar-se com o presente no plano do sincrônico. Cidade e cultura se opõem ao tempo5 (LOTMAN, 1994, p. 11-12).

No referido trecho, Lotman não deixa dúvida sobre o modo pelo qual a heterogeneidade do espaço semiótico da urbe se constrói pela interação entre a sincronia e a diacronia ou, mais precisamente, pelo modo em que, pela sincronia, isto é, por um conjunto de relações que se constitui num determinado momento, se torna possível apreender a diacronia de um conjunto de textos culturais, pertencentes a diferentes temporalidades da cultura, que igualmente intervêm na configuração de novos arranjos textuais por meio do diálogo estabelecido com outros códigos e linguagens.

5 Na tradução espanhola: "Precisamente el poliglotismo semiótico de cualquier ciudad la convierte en campo de diferentes colisiones semióticas, imposibles en otras circunstancias. Al unir códigos y textos diferentes en cuanto a estilo y significación nacional y social, la ciudad realiza hibridaciones, recodificaciones y traducciones semióticas que la transforman en un poderoso generador de nueva información. Fuente de tales colisiones semióticas es no sólo el encuentro sincrónico de formaciones semióticas heterogéneas, sino también la diacronía: las construcciones arquitectónicas, los rituales y ceremonias urbanos, el proprio plan de la ciudad y miles de otros restos de épocas pasadas actúan como programas codificados que generan de nuevo permanentemente los textos del pasado histórico. La ciudad es un mecanismo que recrea una y otra vez su pasado, que obtiene así la posibilidad de encontrarse con el presente en el plano de lo sincrónico. Ciudad y cultura se oponen al tiempo." 
Ainda segundo o autor (LOTMAN, 1996), todo texto cultural é fruto das relações de traduzibilidade e intraduzibilidade operacionalizadas pela fronteira semiótica estabelecida entre, no mínimo, dois sistemas de linguagem ou códigos, de forma que uma das características centrais de todo texto é a "heterogeneidade semiótica"6 (LOTMAN, 1998, p. 14). É também esse poliglotismo que nos permite entender em que medida uma das principais funções exercidas pelo texto se reporta à memória. Para Lotman, a "memória não hereditária de uma coletividade"7 (2000, p. 172) consiste num atributo da própria cultura e dos textos que conferem materialidade a ela. É pela correlação entre os diferentes extratos que compõem um texto que se torna possível apreender uma dupla propriedade intelectiva que caracteriza o funcionamento da memória: armazenar e produzir novas informações, às quais correspondem, respectivamente, uma "memória informativa" e uma "memória criativa (criadora)" (LOTMAN, 1996, p. 158).

No primeiro caso, ao conservar uma informação no decurso do tempo, a memória gera um programa ou um vetor voltado ao futuro, que estabelece formas dominantes de organização de um determinado texto cultural. Isso não significa que tais arranjos sígnicos permaneçam inalterados, mas que, apesar das transformações operacionalizadas em virtude do diálogo estabelecido com o entorno, algo se mantém.

Como o semioticista afirma, trata-se de "alguma invariante de sentido" (LOTMAN, 1996, p. 157) ou, segundo Machado (2013, p. 17), de "invariantes no contexto das variações" passíveis de serem reconhecidas pela presença de um conjunto de "textos constantes"10 (LOTMAN, 1996, p. 157), pelo movimento dos códigos ou pela persistência de determinados modelos e suas respectivas modelizações, tal como discutiremos adiante no âmbito das corralas.

6 Na tradução espanhola: "heterogeneidad semiótica”.

7 Na tradução espanhola: "memoria no hereditaria de una colectividad”.

8 Na tradução espanhola: "memoria informativa" "memoria creativa (creadora)".

9 Na tradução espanhola: "alguna invariante de sentido".

10 Na tradução espanhola: "textos constantes”. 
Com isso, torna-se possível apreender a longa duração de certos textos e códigos culturais, como também a maneira pela qual se cria uma hierarquia de valores num contexto sociocultural específico (LOTMAN, 2000). Longe de ser imutável, tal hierarquização somente pode ser entendida no âmbito das transformações de uma determinada cultura, que, inclusive, podem acarretar a alteração das posições ocupadas por diferentes extratos sígnicos, cujas transformações, como Machado indica (2013, p. 18), exigem a consideração sobre "o que muda e o que permanece".

Em virtude desse funcionamento da memória informativa, uma cultura cria seus próprios parâmetros sobre aquilo que deve recordar, como também sobre o que deve ser esquecido (LOTMAN, 1996). Porém, com o tempo, tal "paradigma memória-esquecimento"ll (LOTMAN, 1996, p. 160) também pode sofrer alterações. A heterogeneidade e a irregularidade que caracterizam a semiosfera exigem a consideração dos mais variados tipos de arranjos sígnicos e/ou fragmentos isolados que, mesmo expelidos de um determinado espaço de relações, não desaparecem da cultura e, pelo diálogo com outros textos e sistemas "contemporâneos", por meio da fronteira semiótica, podem vir a irromper num determinado contexto, porém, com uma nova configuração.

Pela ação do dispositivo mnemônico, "[...] todo pedaço de uma estrutura semiótica ou todo texto isolado conserva os mecanismos de construção de todo o sistema"12 (LOTMAN, 1996, p. 31) que, por sua vez, necessariamente, gera um novo arranjo textual, da mesma forma que mantém traços da sua memória. Dessa forma, aquilo que deve ser "esquecido" não desaparece, visto que subsiste em estado de latência, pronto a irromper num dado contexto e, eventualmente, contribuir para a redefinição dos parâmetros sobre aquilo que deve ser lembrado e esquecido por uma cultura. É esse mecanismo que elucida a atuação da memória criativa, ou seja, a capacidade que todo texto possui para produzir novos arranjos sígnicos e sentidos não previsíveis pelos

11 Na tradução espanhola: “paradigma memoria-olvido”.

$12 \mathrm{Na}$ tradução espanhola: “[...] todo pedazo de una estructura semiótica o todo texto aislado conserva los mecanismos de construcción de todo el sistema.” 
intercâmbios tradutórios que estabelece com o entorno pela fronteira semiótica.

Assim, vista pela perspectiva do espaço semiótico de relações, a cidade deve ser considerada por meio dos diferentes sistemas sígnicos que a constroem, suas respectivas memórias e reverberações na cultura e, como indica Lotman, a arquitetura é um deles. Quanto a isso, não há como desconsiderar que, do ponto de vista semiótico, as corralas se configuram como textos culturais arquitetônicos, cujo dispositivo mnemônico, segundo nossa perspectiva, se articula, primordialmente, por meio de um modelo subjacente ao seu desenho, pelo qual seria possível apreender um vetor para os sentidos que elas produzem na cultura, como é o caso da ideia de coletividade e pertencimento que se constrói em torno de tais habitações.

Conforme apontamos em outro trabalho (NAKAGAWA, 2019), pela perspectiva da ETM, o modelo deve ser visto em consonância com a Cibernética e, como tal, reporta-se a diagramas de relações passíveis de serem edificados tendo em vista a recorrência do modo de aparecer de determinados fenômenos. Trata-se de formas de inteligibilidade que nos levam a apreender a persistência de determinadas modelizações culturais, considerando tanto as suas invariáveis, quanto as suas variáveis. Uma vez formulados, os modelos afastam-se dos fenômenos diretamente relacionados a eles e produzem uma semiose própria, passando a servir de base para a elaboração de inferências hipotéticas sobre possíveis formas de organização da cultura, muitas vezes, destituídas de uma visualidade singular.

V. V. Inavov, outro importante teórico da ETM, considerando a função primordial exercida pela modelização espacial no processo de organização das culturas, expõe um conjunto de modelos passíveis de serem apreendidos no devir das cidades ao longo dos séculos, que indicariam suas diferentes formas de desenvolvimento, levando-se em conta a relação que se estabelece entre "fatores semióticos"13 (IVANOV, 1993, p. 108) constantes e suas variações.

13 Na tradução espanhola: "factores semióticos". 
Para tal, o autor aponta a presença de um conjunto de regularidades manifestas tanto em assentamentos pré-urbanos quanto na urbe propriamente dita, pelas quais seria possível apreender a ação da memória informacional da cultura. Trata-se de dois "tipos geométricos básicos"14 (IVANOV, 1993, p. 109): o quadrangular e o circular, que, não raro, também estariam presentes em modelos pertencentes a outros sistemas. Com isso, Ivanov reporta-se a um dos processos mais elementares relativos à organização de qualquer cultura, ou seja: a configuração do "modelo estrutural do espaço"15 (LOTMAN, 1996, p. 83) e a consequente delimitação entre o espaço "próprio" e o "alheio" que caracterizariam a constituição, a organização e a individuação semiótica de qualquer cidade.

Antes de nos atermos ao significado dessas formas de organização, cumpre ressaltar que, tal como Lotman afirma, a modelização espacial da cultura se caracteriza, essencialmente, por aspectos topológicos. No âmbito da geometria, a topologia reporta-se ao estudo das características de conjuntos que se mantêm inalteradas mesmo quando deformadas, o que permitira identificar relações de conexão, vizinhança e continuidade entre diferentes espaços que, nem sempre, se mostram com clareza. Tal especificação é de fundamental importância para apontarmos que, no âmbito do pensamento semiótico, a delimitação entre o espaço "próprio" e "alheio" não se reporta a uma demarcação topográfica, relativa à construção do espaço físico-construído, mas à dimensão essencialmente sígnica e informacional do espaço.

Assim, tanto o círculo quanto o quadrado devem ser entendidos na sua caracterização topológica, uma vez que, por serem ordenações fechadas, ambos seriam passíveis de proteger o espaço interno contra as ameaças externas, da mesma forma que podem vir a orientar a organização física do espaço da cultura, pois, "a interpretação semântica do modelo da cultura consiste no estabelecimento de correspondências entre seus elementos (espaço, fronteira, pontos) e fenômenos do mundo

14 Na tradução espanhola: "tipos geométricos básicos".

15 Na tradução espanhola: "modelo estructural del espacio".

COMUn. mídia CONSUMO SÃo PAULO, v. 18, N.52, P. 336-363, MAi./AGO. 2021 
objetivo"16 (LOTMAN, 1998, p. 102). Nesse sentido, a esses dois tipos geométricos, poderiam somar-se outros que, por meio de aspectos topológicos comuns, desempenhariam a mesma função. Como Ivanov enfatiza:

[...] as formas concêntricas circulares e quadradas ou, em geral, poligonais, frequentemente são uma questão nem tanto de planificação real como de interpretação simbólica. A concepção idealizada do povo ou de uma cidade como um círculo não supõe obrigatoriamente uma construção circular. A cidade pode ter realmente a forma de um polígono (às vezes de um quadrilátero regular), ou uma estrutura geométrica mais complexa, distinta do círculo, mas que no nível simbólico pode ser descrita como um círculo ou como um quadrado inscrito num círculo (mandala) ${ }^{17}$ (IVANOV, 1993, p. 111).

Nota-se que, por possuírem uma mesma característica topológica, todas a figuras geométricas descritas por Ivanov dizem respeito a uma invariável relativa tanto à arquitetura quanto a formas específicas de organização da urbe, pelas quais se torna possível apreender um traço marcante da ação exercida pela memória da cultura. Ainda que não confundamos cidade com arquitetura, visto que a segunda consiste num dos muitos sistemas que constroem a primeira, pela perspectiva topológica, é possível perceber de que maneira tanto a urbe quanto um determinado desenho arquitetônico podem se estruturar segundo um mesmo modelo e, com isso, se assemelhar em alguns aspectos, dada a relação isomórfica estabelecida entre um e outro. Trata-se, assim, de modelos da cultura que, como Lotman afirma, são “[...] descrições de textos da

16 Na tradução espanhola: "La interpretación semántica del modelo de la cultura consiste en el establecimiento de correspondencias entre sus elementos (espacio, frontera, puntos) y fenómenos del mundo objetivo."

$17 \mathrm{Na}$ tradução espanhola: "[...] las formas concéntricas circulares y las cuadradas o, en general, poligonales a menudo es una cuestión no tanto de planificación real como de interpretación simbólica. La concepción idealizada del pueblo o de la ciudad como un círculo, no supone obligatoriamente una construcción circular. La ciudad puede tener realmente la forma de un polígono (a veces de un cuadrángulo regular), o una estructura geométrica más compleja, distinta del círculo, pero en el nivel simbólico puede ser descrita como un círculo o como un cuadrado inscrito en un círculo (mandala)". 
cultura construídas com ajuda dos recursos da modelização espacial e, em particular, as topológicas [...]"18 (1998, p. 101).

No âmbito do desenho arquitetônico que distingue as corralas situadas no bairro Lavapiés que, conforme enfatizamos, se caracterizam por um pátio central circundado, em geral, por três andares onde se localizam as pequenas habitações, é possível observar a ação de um modelo que se assemelha àquele pontuado por Ivanov: a célula (SENNETT, 2019), caracterizado por um formato quadrangular fechado, em cujo centro há a presença de um pátio. É justamente por meio dela que seria possível apreender a ação da memória que organiza aquela espacialidade, tendo em vista a presença de um vetor que nos permite notar determinadas regularidades concernentes, por exemplo, às relações sociais que ali se articulam e à produção de sentidos e, por outro lado, às reverberações que produzem por meio dos intercâmbios com outros textos.

\section{As corralas e o modelo celular}

Segundo Richard Sennett (2019), em geral, toda cidade possui um "tecido", ou seja, uma ordenação específica que estabelece um direcionamento para a relação que se constrói entre diferentes tipos de edifícios, ruas e espaços abertos. ${ }^{19}$ Dentre os três tipos de tecidos apontados pelo autor, ${ }^{20}$ um deles reporta-se justamente ao celular. Trata-se de uma ordenação que ocorre pela "união dos pátios"21 (SENNETT, 2019, p. 55), de modo que os edifícios construídos se voltam para o interior, e não para a exterioridade da rua. Ao longo da história, tais pátios adquiriram diferentes variações e escalas, uma vez que tanto abarcaram pequenos grupos familiares quanto lugares públicos circundados por grandes muralhas, que agregavam bazares, mercados e igrejas.

18 Na tradução espanhola: “[...] descripciones de textos de la cultura construidas con ayuda de los recursos de la modelización espacial y, en particular, a las topológicas [...]”.

19 Na mesma obra, Sennett faz uma importante distinção entre ville e cité. A primeira reporta-se ao meio construído, ao passo que a segunda diz respeito às relações que se constroem no cotidiano. Os diferentes tecidos encontram-se mais diretamente relacionados à ville.

20 Os outros dois são: ortogonal e agregação.

21 Na tradução espanhola: "unión de los patios". 
Ainda segundo o autor (SENNETT, 2019), esse tipo de organização espacial encontra-se diretamente relacionado à possibilidade de estruturação de formas mais acolhedoras de vida social, dada a sensação de proximidade criada pela intensificação do encontro face a face entre indivíduos pertencentes a pequenos grupos, do qual decorre a possibilidade de irrupção de maneiras mais coletivas e solidárias de organização. É por isso que, não raro, tal habitação foi de importância central para a proteção e resistência de grupos socialmente mais vulneráveis, servindo de "[...] espaço secreto, difícil de penetrar para as autoridades $[. .$.$] "22$ (SENNETT, 2019, p. 57).

É importante enfatizar que, para Lotman, a semiose gerada por qualquer construção arquitetônica não se limita a ela própria, visto que abarca toda uma série "extra-arquitetônica"23 (LOTMAN, 2000, p. 105), que envolve modos de organização sociocultural, rituais e vários outros aspectos, dos quais decorrem a formação de símbolos mnemônicos, que se caracterizam essencialmente pela capacidade "[...] de concentrar em si, conservar e reconstruir a 'lembrança' de seus contextos precedentes"24 (LOTMAN, 1998, p. 156), originando aquilo que Lotman indica ser uma "ressonância simbólica"25 (LOTMAN, 1998, p. 156), característica do funcionamento da memória na cultura.

Nesse sentido, a ideia de uma organização mais comunitária, horizontal e cooperativa de vida social frequentemente associada a modelos celulares, tal como ocorre com as corralas, pode ser encarada como um símbolo mnemônico que se reporta a uma modelização espacial e social muito específica que, há tempos, se mostra presente na cultura e que igualmente permite conhecer uma determinada "visão de mundo", vinculada a modalidades de organização social mais comunais. Como Lotman afirma:

22 Na tradução espanhola: “[...] espacio secreto, difícil de penetrar para las autoridades [...]”.

23 Na tradução espanhola: "extraarquitetónica”.

$24 \mathrm{Na}$ tradução espanhola: "de concentrar en sí, conservar y reconstruir el recuerdo de sus contextos precedentes".

25 Na tradução espanhola: "resonancia simbólica". 
O espaço arquitetônico vive uma dupla vida semiótica. Por um lado, modeliza o universo: a estrutura do mundo construído e habitável é transladada ao mundo em sua totalidade. Por outro, é modelizado pelo universo: o mundo criado pelo homem reproduz sua ideia da estrutura global do mundo. A isso está ligado o elevado simbolismo de tudo o que, de um ou outro modo, pertence ao espaço da habitação criado pelo homem ${ }^{26}$ (LOTMAN, 2000, p. 103).

Pela modelização celular subjacente às corralas e pela memória vinculada a ela, estabelece-se uma hierarquia de valores em que o coletivo necessariamente deve se sobrepor ao individual, o que não significa anulá-lo. Ainda com relação a esse aspecto, como Lotman (2013) aponta, o coletivo apenas pode ser entendido como tal quando se consideram as relações de semelhanças e diferenças que se colocam entre distintas individualidades, de modo que qualquer coletividade se caracteriza, essencialmente, pela ambivalência. Mesmo que, em determinadas circunstâncias, uma das duas tendências possa vir a ser dominante, uma não subsiste sem a outra. Além do mais, segundo os princípios do isomorfismo que pautam o pensamento lotmaniano, toda individualidade também se equipara ao todo ao qual faz parte, da mesma forma que traz em si um germe do coletivo, de maneira que:

Aqui, o indicador quantitativo é ativado e os comportamentos se tornam a base de um senso de partição e participação. O indivíduo experimenta a si mesmo simultaneamente como um todo feito à semelhança do universal e como uma parte, que forma a base da autoconsciência humana. A autoconsciência não é uma superestrutura "exterior", mas a realidade organizadora da vida humana cotidiana ${ }^{27}$ (LOTMAN, 2013, p. 48).

26 Na tradução espanhola: "El espacio arquitectónico vive una doble vida semiótica. Por una parte, modeliza el universo: la estructura del mundo de lo construido y habitable es trasladada al mundo en su totalidad. Por otra, es modelizado por el universo: el mundo creado por el hombre reproduce su idea de la estructura global del mundo. A esto está ligado el elevado simbolismo de todo lo que de uno u otro modo pertenece al espacio de la vivienda creado por el hombre."

27 Na tradução inglesa: "Here the quantitative indicator is activated and behaviours become the basis of a sense of partition and participation. The individual experiences him or herself simultaneously as a whole made in the likeness of the universal and as a part, which forms the basis of human self-consciousness. Self-consciousness is not an "exterior" superstructure but the organising reality of everyday human life". 
Nesse sentido, nota-se que a modelização celular subjacente às corralas constrói uma memória caracterizada por um dominante relacionado a um senso de participação, em que o indivíduo é, ao mesmo tempo, "eu e nós", da mesma forma que a "dupla vida" do espaço arquitetônico tanto traduz o modo como os sujeitos percebem o mundo quanto produz as espacialidades da cultura. Delimita-se assim o que deve ser lembrado, apesar das significativas transformações sofridas ao longo da história daquilo que se entende por individualidade e coletividade.

No âmbito da discussão proposta neste artigo, isso pode ser apreendido, sobretudo, quando se busca discriminar a semiose que o signo mnemônico relacionado às corralas produz ou, ainda, suas possibilidades de reverberação simbólica, como aponta Lotman. Mais especificamente, vejamos como esse processo pode ser observado no cartaz das Fiestas Populares de Lavapiés de 2019.

\section{A redefinição da ideia de coletividade}

Conforme pode ser observado, a ilustração (figura 7) retrata uma corrala adornada com duas cordas: em uma, há a presença de bandeirinhas coloridas e, na outra, dentre uma série de peças de roupas penduradas, destacam-se duas camisetas com a marca do movimento feminista e uma calça com as cores verde, amarelo e vermelho, que também estão presentes na bandeira do Senegal, país de onde deriva um dos principais grupos de imigrantes que vivem no bairro ${ }^{28}$, além de uma "bandeira arco-íris”, símbolo mundialmente conhecido do orgulho LGBTQ+.

28 Os grupos mais representativos são, respectivamente, provenientes de Bangladesh (20,56\%), Marrocos (6,97\%), Equador (6,22\%) e Senegal (4,06\%). Fonte: OSORIO, 2017. 
Figura 7: Cartaz das Fiestas Populares de Lavapiés 2019

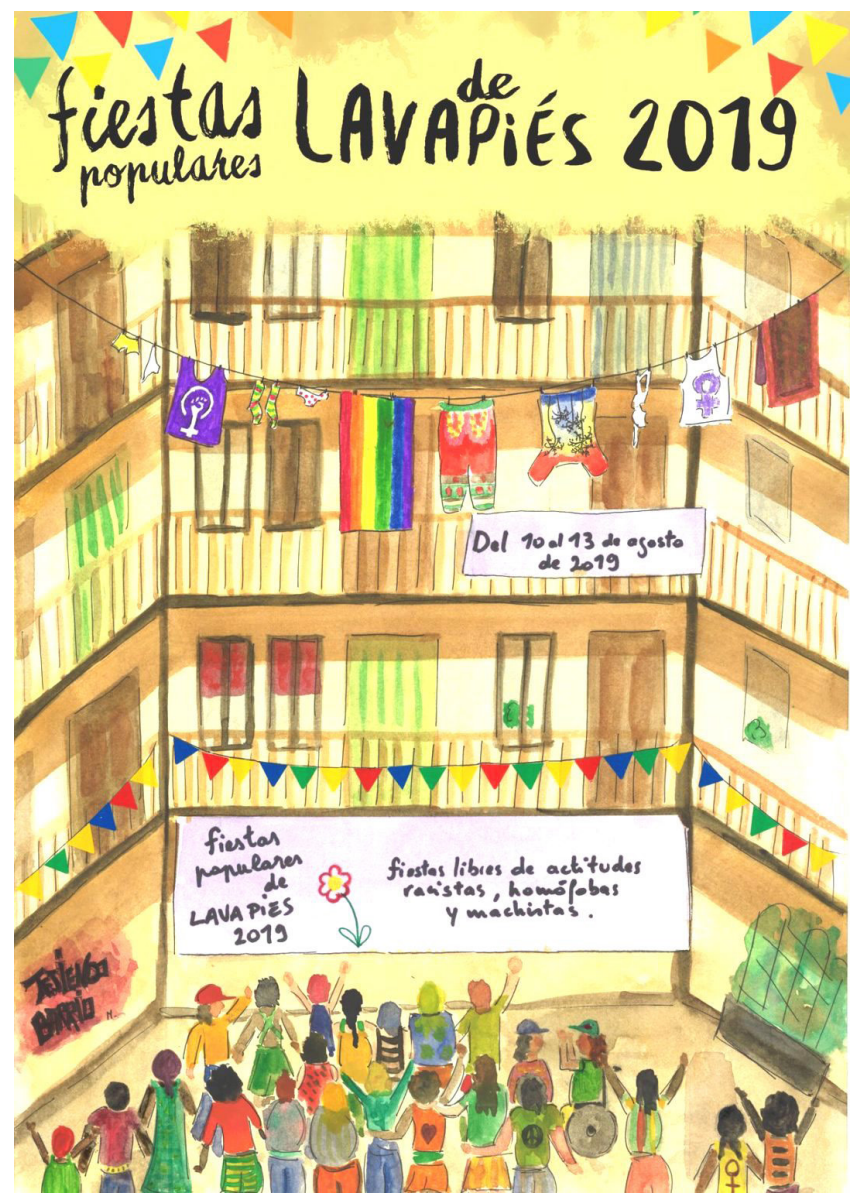

Fonte: Autora

Na parte inferior da peça, ao centro, há a reunião de pessoas pertencentes a diferentes etnias com os braços estendidos, voltadas a um cartaz em que estão as frases "festas populares de Lavapiés" de 2019 e "festas livres de atitudes racistas, homofóbicas e machistas”. À esquerda, há ainda a frase "tecendo bairro". ${ }^{29}$

29 Na versão espanhola: Fiestas populares de Lavapiés" de 2019; "fiestas libres de actitudes racistas, homofóbicas y machistas"; "tejiendo barrio". 
É importante ressaltar como as festas são definidas no referido cartaz, ou seja, como celebrações pautadas pela convivência e pela tolerância entre singularidades que abarcam distintas etnias, gêneros, sexualidades e lutas sociais. Quanto a isso, cumpre ressaltar que cerca de 32\% dos moradores de Lavapiés são imigrantes, o que o torna o bairro com a maior concentração de estrangeiros na capital espanhola (no restante da cidade, esse percentual chega a 16\%). A região também é conhecida pela presença de inúmeras ocupações e coletivos, além de reunir numerosos movimentos voltados à luta pelos direitos das minorias. Segundo Fernandéz (2013), tamanha é a tendência do bairro para o ativismo que há um termo para designá-lo: el rollito.

Tal como foi representada e traduzida pelos códigos gráficos, pode-se inferir que a corrala presente na peça possui uma forma poligonal, ainda que, na ilustração, sejam mostrados apenas três lados e dois vértices, cuja posição busca simular a tridimensionalidade da construção arquitetônica no espaço bidimensional da peça gráfica. Reunidos no pátio central, os indivíduos retratados estão de frente para os dizeres que se encontram centralizados na peça, porém, de costas para aquele que contempla a totalidade do cartaz. Assim, ao se posicionar diante dele, o observador coloca-se na mesma posição daqueles que estão ali retratados, passando, assim, a fazer parte do grupo. É essa ação que "permite" que a figura geométrica/corrala se "complete", expandindo-se para fora do cartaz, ou seja: por meio daquele que se coloca como parte do ajuntamento ali retratado, de modo que o espaço tridimensional da urbe e, sobretudo, do bairro, em cujas paredes foram afixadas centenas de cartazes, se transforme numa grande corrala.

Pela tradução operacionalizada pelos códigos gráficos, nota-se de que maneira se intenta construir um espaço tridimensional pela bidimensionalidade do cartaz, dos quais decorre a emersão de sentidos relacionados à modelização espacial subjacente às corralas. Como Lotman afirma, um aspecto central concernente à semiótica espacial diz respeito ao seu "caráter vetorial" ${ }^{30}$ que, necessariamente, implica uma

30 Na tradução espanhola: "carácter vectorial". 
“orientação”, pois “[...] um traço tipológico será a orientação à mirada, o ponto de vista de certo observador ideal, identificável, diria-se com a própria cidade"31 (2000, p. 109). Trata-se, portanto, de uma comunicabilidade indissoluvelmente relacionada ao traço mnemônico do espaço que, mesmo em diálogo com contextos diversos, é capaz de ativar sentidos construídos no devir do tempo.

Por consequência, não há como desconsiderar a memória relacionada à ideia de coletividade presente no cartaz, ao mesmo tempo em que o contexto ali retratado implica a redefinição daquilo que se entende por coletividade, que deixa de se limitar a pequenos grupos e adquire uma amplitude social muito mais ampla, da mesma forma que passa a considerar as singularidades que formam o todo. Quanto a isso, é importante ressaltar que, para Lotman (2013), a delimitação do individual e do coletivo somente pode ser feita quando se leva em conta o contexto mais amplo que envolve ambos. Assim, se, no passado, as corralas se reportavam a pequenos grupos constituídos por um conjunto de famílias, pela ressonância propiciada pelo signo mnemônico, tal como ocorre na peça gráfica, o coletivo passa a abarcar grupos mais amplos que envolvem diferentes etnias e posicionamentos políticos, elucidando, ao mesmo tempo, uma característica que distingue não apenas a região de Lavapiés em Madrid, mas inúmeros outros bairros presentes em diferentes megalópoles.

Ao mesmo tempo, a peça parece apontar que tal concepção de coletividade, longe de apagar as diferenças, emerge em meio a elas. Conforme indica Lazzarato, na atualidade, o "estar junto" deve ser entendido, primordialmente, pelas relações que emergem em meio à "multiplicidade das singularidades" (2006, p. 30) que, cada vez mais, irrompem no atual cenário geopolítico. É essa ambivalência que gera relações pautadas pela cooperação, potencializadas pelos encontros acontecimentais voltados a “[...] uma experimentação de dispositivos de estar junto [...]"

31 Na tradução espanhola: “[...] un rasgo tipológico de ella será la orientación de la mirada, el punto de vista de cierto observador ideal, identificable, diríase, con la ciudad misma”. 
que favoreçam "[...] o encontro das singularidades e o agenciamento de mundos diferentes" (LAZZARATO, 2006, p. 228).

Retomando o referido cartaz, nota-se que a diversidade que ele busca representar não rompe com a memória relacionada às corralas e à hierarquia de valores subjacente a elas, porém, situa que, na atualidade, o sentido de coletividade e pertencimento não pode ser dissociado da consideração das singularidades. Com isso, percebe-se de que maneira, apesar das suas variações, a ideia de coletividade parece persistir no modo de configuração da cidade, o que, segundo Lotman, faz com que ela se oponha ao tempo.

Além disso, a especificidade da configuração sígnica da peça, que predetermina de forma muito clara a posição a ser ocupada pelo observador, resulta por igualmente modelizar um determinado sentido de pertencimento somente passível de ser construído pela dimensão sensória daquele que se coloca diante dela no espaço da urbe, de modo que “[...] a mensagem só ‘tem' sentido se 'for' sentida” (MACHADO, 2005, p. 290) na especificidade daquele contexto.

Não se pode perder de vista que o envolvimento sensório promovido por um determinado meio e seu sistema de codificação é um dos fundamentos do conceito de meio comunicacional proposto por Marshall McLuhan $(2005,1969)$. Para o autor, ao se constituir como uma extensão de um ou mais órgãos sensoriais, todo meio gera uma série de transformações na dimensão perceptocognitiva humana e nas mais variadas esferas da sociedade e da cultura. São esses efeitos e/ou mudanças que geram o ambiente que, por sua vez, define o meio.

Vale lembrar que, para o autor (McLUHAN; STAINES, 2005, p. 80), a cidade se constitui como um meio que promove a distensão de diferentes órgãos sensoriais, de modo que, como ele afirma "[...] nossas tecnologias simularam durante milhares de anos não o corpo, mas fragmentos dele. Só na cidade é que a imagem do corpo humano como uma unidade se tornou manifesta”. Pode-se dizer que, segundo o teórico canadense, a urbe tanto se constitui como uma extensão do sensório quanto intervém para redefini-lo. 
Ao incitar o desenho de uma corrala que só se constrói a partir da singularidade de cada corpo, mediante a reordenação da linguagem bidimensional para o tridimensional, a peça gráfica das Fiestas Populares de Lavapiés de 2019 promove, justamente, o envolvimento sensório que, segundo McLuhan, constitui um dos principais atributos do funcionamento da cidade como meio comunicativo, ao qual correspondem formas menos especializadas de percepção e raciocínio. Com isso, nota-se de que maneira a peça não apenas contribui para construir a cidade como ela própria funciona como um metatexto sobre o qual se pode apreender o próprio funcionamento da urbe como meio comunicativo e como espaço semiótico de relações.

Tal aspecto também nos ajuda a entender a dimensão comunicativa da cidade pela perspectiva semiótica. Conforme apontamos anteriormente, a ideia de "complicação progressiva" que os semioticistas da ETM associam à comunicação ${ }^{32}$ encontra-se diretamente relacionada ao modo pelo qual diferentes sistemas operacionalizam a tradução da memória informacional, de forma a gerar a emersão de textos culturais cada vez mais heterogêneos e, muitas vezes, imprevisíveis, pois “[...] a transmissão de mensagem não é a única função do mecanismo comunicativo, nem do mecanismo cultural em seu conjunto. Estes, ao mesmo tempo realizam a produção de 'novas' mensagens [...]"33 (LOTMAN, 1996, p. 67).

Nesse sentido, a comunicação é entendida pelos mais variados processos de interação operacionalizados pela fronteira no espaço da semiosfera, por meio dos quais uma informação é traduzida em linguagem e código, ampliando assim os sentidos que ela é capaz de produzir. Como lembra Machado (2005, p. 288), não se pode perder de vista que “[...] uma das propriedades inalienáveis da comunicação é a capacidade

32 Lotman (1996) situa a comunicação como parte do mecanismo inteligente da cultura. Para construir sua formulação, o autor toma por base os dois hemisférios cerebrais, cujo funcionamento caracteriza-se por relações de assimetria e intercâmbio entre individualidades semióticas distintas.

33 Na tradução espanhola: “[...] la transmisión del mensaje no es la única función del mecanismo comunicativo, ni del mecanismo cultural en su conjunto. Éstos, al mismo tiempo, realizan una producción de nuevos mensajes [...]". 
de organizar informação em linguagens de diferentes codificações”, sem as quais ela sequer ganharia materialidade na cultura.

Assim, ao promoverem diferentes formas de tradução da memória informacional característica da modelização celular, tanto as corralas quanto a peça gráfica elucidam distintos processos comunicacionais que constroem o espaço semiótico urbe, da mesma forma que amplificam os sentidos relacionados à ideia de comunidade como também do próprio funcionamento da cidade como meio comunicativo. Pela perspectiva dos semioticistas da ETM, se a memória constrói as espacialidades da urbe é porque, antes de tudo, ela se insere num processo comunicacional entre distintas esferas culturais, pelas quais um símbolo mnemônico é traduzido e, com isso, tanto mantém alguns traços distintivos, quanto amplia-se na relação que estabelece com o entorno.

\section{Considerações finais}

Conforme pontuamos, tanto o desenho arquitetônico das corralas quanto o cartaz das Fiestas Populares de Lavapiés se configuram como textos culturais, numa dinâmica na qual o segundo se constitui como uma reverberação do símbolo mnemônico subjacente à modelização espacial celular característica do primeiro. Apreender tal atuação da memória não hereditária, por sua vez, exige pensar o espaço semiótico de relações que se estabelece entre ambos, uma vez que apenas em relação com outros um texto é capaz de produzir sentidos. Dessa forma, a compreensão das corralas como textos culturais mnemônicos advém não do espaço físico construído dessas habitações, mas, sim, da semiose que a modelização celular produz na cultura por meio de processos comunicacionais, das quais decorrem determinadas formas de organização social. Quanto a isso, é importante ressaltar a recorrência da modelização espacial das corralas em determinadas formas de ocupação de espaços públicos, como, inclusive, verifica-se em muitos grupos imigrantes que residem no bairro Lavapiés, cuja discussão extrapola o escopo deste artigo.

Ainda com relação ao vínculo existente entre modelização, memória, comunicação e processos de organização social, não se pode perder 
de vista que, tal como Machado afirma, “[...] a cultura como memória coletiva é igualmente um sistema modelizante que age sobre o comportamento. Nesse caso, é um programa que visa o futuro, uma vez que as regras semióticas de organização da experiência da vida visam o comportamento" (2003, p. 163). Em conformidade com tal pensamento, nota-se que a ação exercida pelas corralas como signo arquitetônico da memória e sistema constitutivo da urbe decorre, sobretudo, da sua série "extra-arquitetônica", capaz de incitar determinadas formas de interação com a urbe. Com isso, pode-se apreender de que maneira a modelização agenciada por intercâmbios comunicacionais se interpõe no processo de interação social, de modo a suscitar a constituição de determinados tipos de vínculos que, apesar dos seus contínuos devires, não rompem com o passado, mas, sim, o ressignificam.

\section{Referências}

DEBORD. Guy. Teoria da Deriva. In: JAQUES, Paola Berenstein (Org.). Apologia da deriva: escritos situacionistas sobre a cidade. Rio de Janeiro: Casa da Palavra, 2003, p. 87-91.

FERNÁNDEZ, Jorge. Las políticas de gentrificación en la ciudad neoliberal. Nuevas clases medias, producción cultural y gestión del espacio público. El caso de Lavapiés en el centro histórico de Madrid. 2013. 353 f. Tese (Doctorado en Teoría Sociológica) - Universidad Complutense de Madrid, Madrid, 2013.

FERRARA, Lucrécia D’Alessio. Comunicação. Espaço. Cultura. São Paulo: Annablume, 2008.

FERRARA, Lucrécia D’Alessio. Design em espaços. São Paulo: Rosari, 2002.

IVANOV, Viacheslav V. Contribución al estudio semiótico de la historia cultural de la gran ciudad. Escritos - Revista del Centro de Ciencias de Lenguaje, México D. F., n. 9, p. 107-127, jan./dez., 1993.

JAKOBSON, Roman. O dominante. In: LIMA, Luiz Costa (Org.). Teoria da literatura em suas fontes. Rio de Janeiro: Francisco Alves, 1983, p. 485-491.

KULL, Kalevi. Semiosfera e a ecologia dual: paradoxos da comunicação. In: MACHADO, Irene (Org.). Semiótica da cultura e semiosfera. São Paulo: Anablume, 2007, p. 69-79.

LAZZARATO, Maurizio. As revoluções do capitalismo. Rio de Janeiro: Civilização Brasileira, 2006.

LOTMAN, Iuri. La semiosfera I. Semiótica de la cultura y del texto. Madrid: Ediciones Catedra, 1996. 
LOTMAN, Iuri. La semiosfera II. Semiótica de la cultura, del texto, de la conducta y del espacio. Madrid: Ediciones Catedra, 1998.

LOTMAN, Iuri. La semiosfera III. Semiótica de las artes y de la cultura. Madrid: Ediciones Catedra, 2000.

LOTMAN, Iuri. Símbolos de Petesburgo y problemas de semiótica urbana. Revista de Occidente, Madrid, n. 156, p. 05-22, maio 1994.

LOTMAN, Iuri. The unpredictable workings of culture. Tallin: TLU Press, 2013.

MACHADO, Irene. Escola de semiótica. A experiência de Tártu-Moscou para o Estudo da Cultura. Cotia: Ateliê, 2003.

MACHADO, Irene. O método semiótico-estrutural na investigação dos sistemas da cultura. In: SILVA, Alexandre R.; NAKAGAWA, Regiane M. O. Semiótica da comunicação. São Paulo: Intercom, 2013, p. 16-41.

MACHADO, Irene. O ponto de vista semiótico. In: HOHLFELDT, Antonio; MARTINO, Luiz C.; FRANÇA, Vera V. Teorias da comunicação. Conceitos, escolas e tendências. Petrópolis: Vozes, 2005, p. 279-309.

MACHADO, Irene. Semiótica como teoria da comunicação. In: WEBER, Maria Helena; BENTZ, Ione; HOHLFELDT, Antonio. Tensões e objetos na pesquisa em comunicação. Porto Alegre: Sulina, 2002, p. 209-234.

McLUHAN, Marshall. Contraexplosion. Buenos Aires: Editorial Paidós, 1969.

McLUHAN, Stephanie; STAINES, David (Orgs.). McLuhan por McLuhan: conferências e entrevistas. Rio de Janeiro: Ediouro, 2005.

NAKAGAWA, Regiane M. O. Lotman e o procedimento modelizador: a formulação sobre a "invariante intelectual" da cultura. Bakhtiniana. Revista de estudos do discurso. São Paulo, v. 14, n. 4, p. 121-140, out./dez., 2019.

OSORIO, Carlos. Lavapiés y El rastro. Madrid: Temporae, 2017.

SENNETT, Richard. Construir y habitar. Ética para la ciudad. Barcelona: Editorial Anagrama, 2019. 


\section{Sobre a autora}

Regiane Miranda de Oliveira Nakagawa - Doutora em Comunicação e Semiótica, realizou estágio pós-doutoral na ECA/USP (bolsa Fapesp) e na Universidade Complutense de Madrid. Professora permanente do PPGCOM da UFRB. Professora permanente do PPGCOM da UFRB e do Centro de Cultura, Linguagens e Tecnologias Aplicadas - CECULT da UFRB. Foi coordenadora do GP Semiótica da Comunicação da Intercom, de 2011 a 2014.

Data de submissão: 14/04/2020

Data de aceite: 24/08/2020 